\title{
LEPR gene GIn223Arg polymorphism and type 2 diabetes mellitus: a meta-analysis of 3,367 subjects
}

\author{
Yan-Yan Li ${ }^{1, *}$, Hui Wang ${ }^{2, *}$, Xin-Xing Yang ${ }^{1}$, Jing-Jing Wu ${ }^{3}$, Hong-Yu Geng ${ }^{1}$, Hyun \\ Jun Kim ${ }^{4}$, Zhi-Jian Yang ${ }^{2}$ and Lian-Sheng Wang ${ }^{2}$ \\ ${ }^{1}$ Department of Gerontology, First Affiliated Hospital of Nanjing Medical University, Nanjing 210029, China \\ ${ }^{2}$ Department of Cardiology, First Affiliated Hospital of Nanjing Medical University, Nanjing 210029, China \\ ${ }^{3}$ Department of Nephrology, First Affiliated Hospital of Nanjing Medical University, Nanjing 210029, China \\ ${ }^{4}$ Department of Physiology, University of Cincinnati, Cincinnati, OH 45267, United States of America \\ *These authors have contributed equally to this work \\ Correspondence to: Yan-Yan Li, email: lyynjmu123@126.com \\ Keywords: leptin receptor, Gln223Arg, polymorphism, type 2 diabetes mellitus \\ Received: February 09, $2017 \quad$ Accepted: May 22, $2017 \quad$ Published: June 27, 2017 \\ Copyright: Li et al. This is an open-access article distributed under the terms of the Creative Commons Attribution License 3.0 \\ (CC BY 3.0), which permits unrestricted use, distribution, and reproduction in any medium, provided the original author and source \\ are credited.
}

\section{ABSTRACT}

Background: The Leptin receptor (LEPR) GIn223Arg gene polymorphism has been associated with an increased susceptibility to Type 2 diabetes mellitus (T2DM). Results from various studies, however, are inconsistent.

Objective and methods: To better elucidate the association of LEPR GIn223Arg gene polymorphism with T2DM in the Chinese population, a meta-analysis of 3,367 subjects from seven independent studies was performed. The pooled odds ratios (ORs) and corresponding $95 \%$ confidence intervals (95\% CI) were evaluated by the fixed-effects model.

Results: A significant relationship between LEPR GIn223Arg gene polymorphism and T2DM in the Chinese population was found under allele (OR: 1.432, 95\% CI: 1.211-1.694, $P=2.67 \times 10^{-5}$ ), dominant (OR: $1.466,95 \%$ CI: $1.215-1.769, P=6.33 \times 10^{-}$ ${ }^{5}$ ), recessive (OR: 0.539, 95\% CI: 0.303-0.960, $\mathrm{P}=0.036$ ), heterozygous (OR: 0.700 , 95\% CI: 0.577-0.849, $\mathrm{P}=3.06 \times 10^{-4}$ ), and homozygous (OR: $0.472,95 \% \mathrm{CI}: 0.265-$ $0.839, P=0.011)$ genetic models.

Conclusions: LEPR GIn223Arg gene polymorphism was associated with an increased risk of T2DM in the Chinese population. Therefore, Chinese carriers of the G allele of LEPR GIn223Arg gene polymorphism may be more susceptible to T2DM than the general population.

\section{INTRODUCTION}

The most recent survey from the Chinese Diabetes Society shows that the overall prevalence of diabetes mellitus (DM) has increased to $11.6 \%$ in the Chinese adult population, making the number of DM patients in China 114 million. This suggests that China, as a country, has the most DM patients in the world [1]. Type 2 diabetes mellitus (T2DM) is a chronic disease associated with abnormal glucose metabolism due to insulin resistance. The pathogenesis of the disease is complicated due to the dynamic interplay between both genetic and environmental factors.

Leptin is peptide hormone secreted by adipose tissue and while it is most famous as the mediator for the sensation of satiety, it also helps regulate energy metabolism and body lipid homeostasis. It also regulates insulin secretion through two distinct mechanisms. It concurrently inhibits parasympathetic nervous system and excites the sympathetic by inhibiting the expression of neuropeptide $Y$ (NPY) gene product, ultimately reducing insulin secretion. 
Table 1: Characteristics of the investigated studies of the association between leptin receptor (LEPR) gene GIn223Arg polymorphism and type 2 diabetes mellitus (T2DM) in the Chinese population

\begin{tabular}{|c|c|c|c|c|c|c|c|c|c|c|c|}
\hline \multirow[t]{2}{*}{ Author } & \multirow[t]{2}{*}{ Year } & \multirow[t]{2}{*}{ Region } & \multicolumn{3}{|c|}{ T2DM } & \multicolumn{3}{|c|}{ Control } & \multirow[t]{2}{*}{ Matching criteria } & \multirow{2}{*}{$\begin{array}{c}\text { sample } \\
\text { size(T2DM / } \\
\text { control) }\end{array}$} & \multirow[t]{2}{*}{$\mathbf{P}_{\text {HWE }}$} \\
\hline & & & GG & GA & $\mathbf{A A}$ & GG & GA & $\mathbf{A A}$ & & & \\
\hline Liao WL [11] & 2012 & Taiwan & 796 & 194 & 8 & 36 & 8 & 1 & Ethnicity & $998 / 45$ & $>0.05$ \\
\hline Fang MZ [6] & 2011 & Yunnan & 169 & 64 & 6 & 150 & 116 & 20 & Ethnicity, TC, LDL & $239 / 286$ & $>0.05$ \\
\hline Shi XH [7] & 2005 & Beijing & 283 & 49 & 1 & 310 & 80 & 5 & Ethnicity & $333 / 395$ & $>0.05$ \\
\hline Xie P [12] & 2002 & Jiangsu & 74 & 10 & 2 & 69 & 17 & 0 & Ethnicity & $86 / 86$ & $>0.05$ \\
\hline Ying $\mathrm{J}$ [5] & 2009 & Hubei & 80 & 24 & 0 & 89 & 21 & 1 & Ethnicity & $104 / 111$ & $>0.05$ \\
\hline Gan RT [13] & 2012 & Heilongjiang & 111 & 33 & 4 & 121 & 47 & 4 & Age, sex, ethnicity & $148 / 172$ & $>0.05$ \\
\hline Jiang B [14] & 2014 & Jilin & 140 & 34 & 3 & 117 & 33 & 3 & $\begin{array}{l}\text { Age, sex, HDL, } \\
\text { LDL, ethnicity }\end{array}$ & $177 / 153$ & $>0.05$ \\
\hline
\end{tabular}

T2DM: type 2 diabetes mellitus; TC: total cholesterol; LDL: low density lipoprotein-cholesterol; HDL: high density lipoproteincholesterol;

PCR-RFLP: polymerase chain reaction-restriction fragment length polymorphism;

PCR-RFLP and case-control study design were adopted in the above studies.

Leptin also binds with leptin receptor (LEPR) located on pancreatic beta cells to regulate insulin secretion $[2,3]$.

The LEPR gene, located on the chromosome $1 \mathrm{p} 31$, spans more than $70 \mathrm{~kb}$, contains 20 exons and 19 introns, and encodes for 1165 amino acids. Though there are many mutations and polymorphisms in the human $L E P R$ gene, the polymorphisms sites have been limited almost exclusively to the 20 exons of the LEPR gene. The Gln223Arg gene polymorphism specifically is caused by the substitution of the adenine at the $668^{\text {th }}$ position by a guanine, mutating the $223^{\text {rd }}$ amino acid, an arginine, to be replaced by a glutamine. This mutation is located on the $6^{\text {th }}$ exon of the protein and may impair signal transduction enough to increase susceptibility to T2DM [4].

Although many studies on the relationship between the LEPR Gln223Arg gene polymorphism and T2DM have been conducted in the Chinese population, results are contradictory. In 2009, Ying et al. reported the A allele of $L E P R$ Gln223Arg gene polymorphism to be associated with an increased risk of T2DM [5]. In contrast, Fang et al found that the $\mathrm{G}$ allele of $L E P R$ Gln223Arg gene polymorphism to be a risk factor for the T2DM in 2011[6]. Shi et al obtained the similar conclusion in 2005 [7].

In the current meta-analysis, data from 2,084 T2DM patients and 1,283 controls was analyzed to further elucidate the relationship between LEPR Gln223Arg gene polymorphism and T2DM in the Chinese population.

\section{RESULTS}

\section{Studies and populations}

Publication years of the included studies ranged from 2002 to 2014 (last research updated on May 15,
2017). Of the 16 papers retrieved by the initial search, seven met inclusion criteria. Among the nine excluded studies, three studies were excluded due to control groups that deviated from Hardy-Weinberg equilibrium (HWE). Three studies were reviews and an additional three studies did not analyze either T2DM or the LEPR Gln223Arg gene polymorphism. Among the ten included studies, three studies deviated from the HWE [8-10] (Figure 1). The full data set was represented by 2,084 T2DM patients and 1,283 controls (Table 1) [5-7, 11-14] from seven different provinces: Beijing, Jiangsu, Yunnan, Hubei, Heilongjiang, Jilin and Taiwan. All of the included studies received at least seven stars using NOS.

\section{Pooled analyses}

There was a significant relationship between $L E P R$ Gln223Arg gene polymorphism and T2DM in the Chinese population under allele (OR: 1.432, 95\% CI: 1.211-1.694, $\mathrm{P}=2.67 \times 10^{-5}$ ), dominant (OR: $1.466,95 \% \mathrm{CI}: 1.215-1.769$, $\mathrm{P}=6.33 \times 10^{-5}$ ), recessive (OR: $0.539,95 \%$ CI: $0.303-0.960$, $\mathrm{P}=0.036$ ), heterozygous (OR: $0.700,95 \% \mathrm{CI}: 0.577-0.849$, $\mathrm{P}=3.06 \times 10^{-4}$ ), homozygous (OR: $0.472,95 \% \mathrm{CI}: 0.265$ $0.839, \mathrm{P}=0.011)$. No significant heterogeneity was detected under all five genetic models $(\mathrm{P}>0.05)$ (Figures 2-6, Table 2).

\section{Bias diagnostics}

The publication bias of the individual studies was assessed by using an Egger's test. No significant difference was detected, indicating that there was minimal publication bias in the current meta-analysis under the heterozygous genetic model $(\mathrm{T}=1.77, \mathrm{P}=0.136)$ (Figure 7). 


\section{DISCUSSION}

In the current meta-analysis, we observed a significant association between the LEPR Gln223Arg gene polymorphism and T2DM in the Chinese population under the allele (OR: 1.432), dominant (OR: 1.466), recessive
(OR: 0.539), heterozygous (OR: 0.700), and homozygous (OR: 0.472) genetic models. The fixed genetic model was used exclusively due to the lack of heterogeneity between studies. We, therefore, concluded that the Chinese individuals with the $\mathrm{G}$ allele of LEPR Gln223Arg gene polymorphism may be predisposed to T2DM.

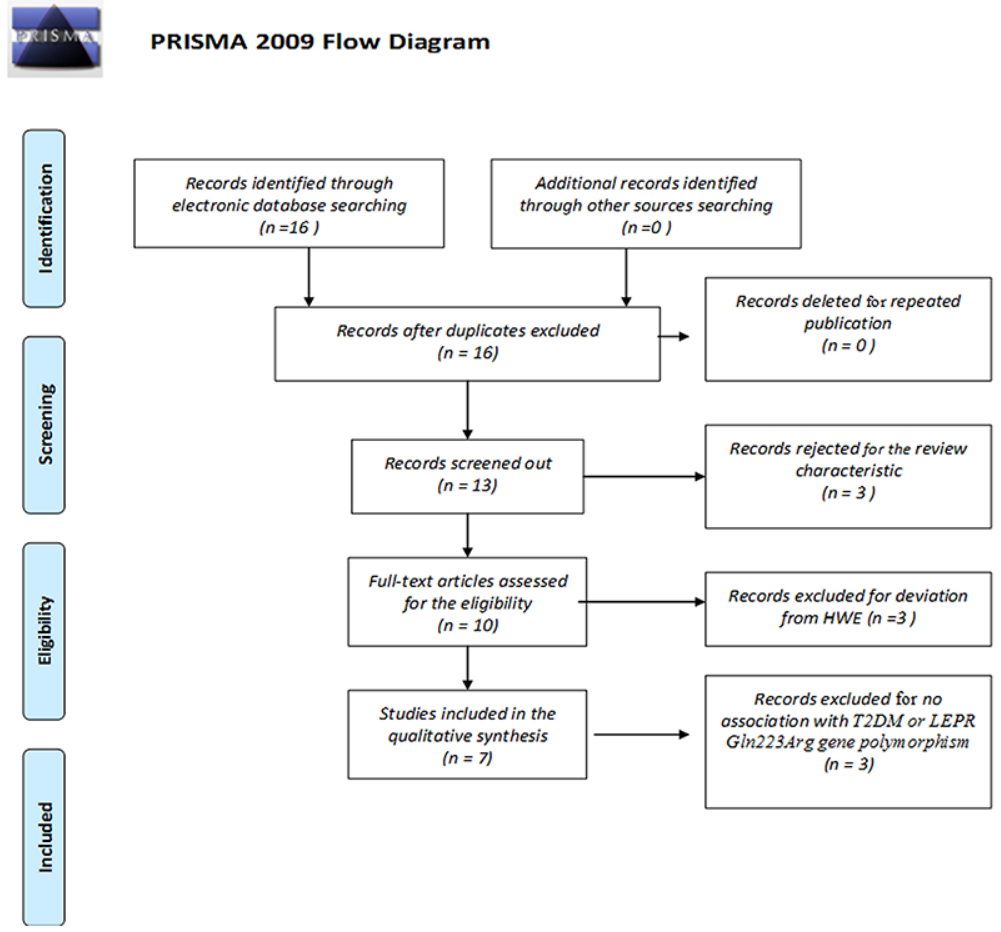

Figure 1: PRISMA 2009 flow diagram.

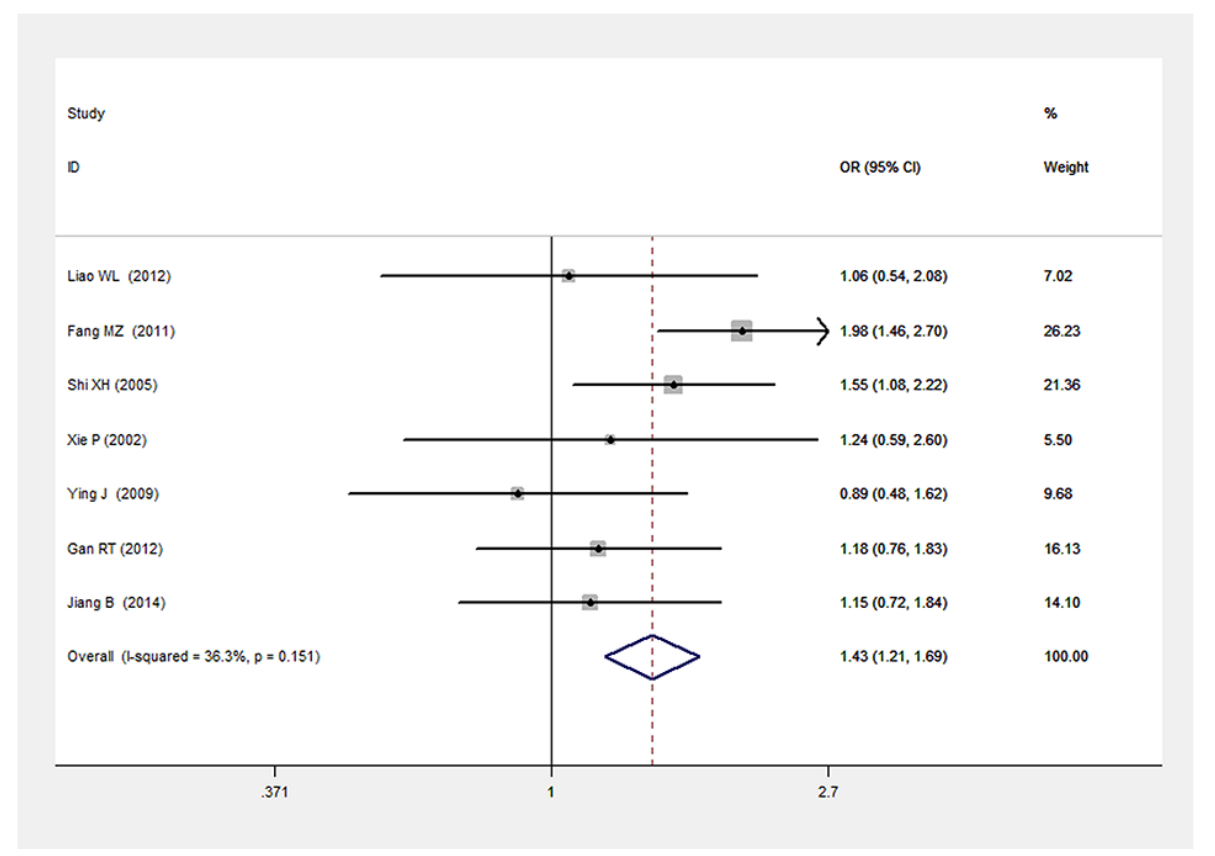

Figure 2: Forest plot of T2DM associated with LEPR GIn223Arg gene polymorphism under an allele genetic model (G vs. A). 


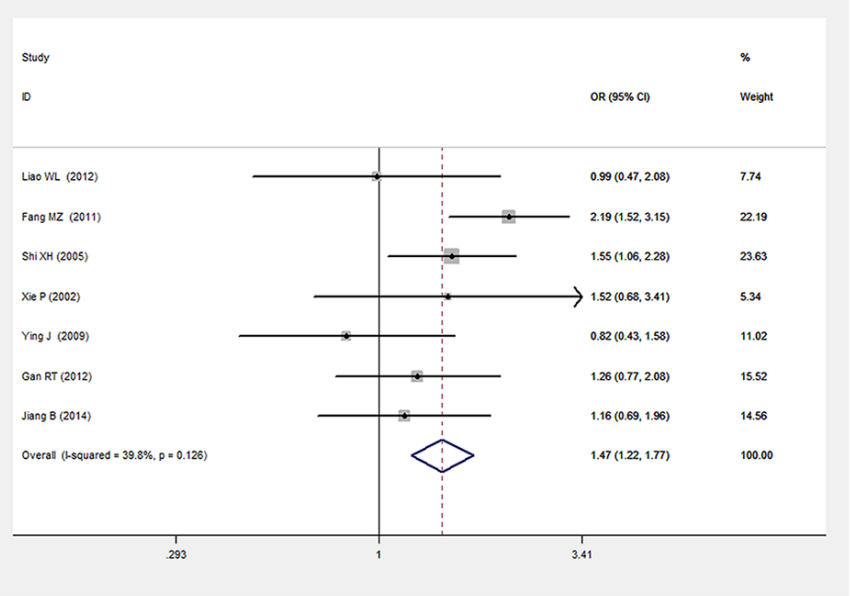

Figure 3: Forest plot of T2DM associated with $L E P R$ GIn223Arg gene polymorphism under a dominant genetic model (GG vs. GA+AA).

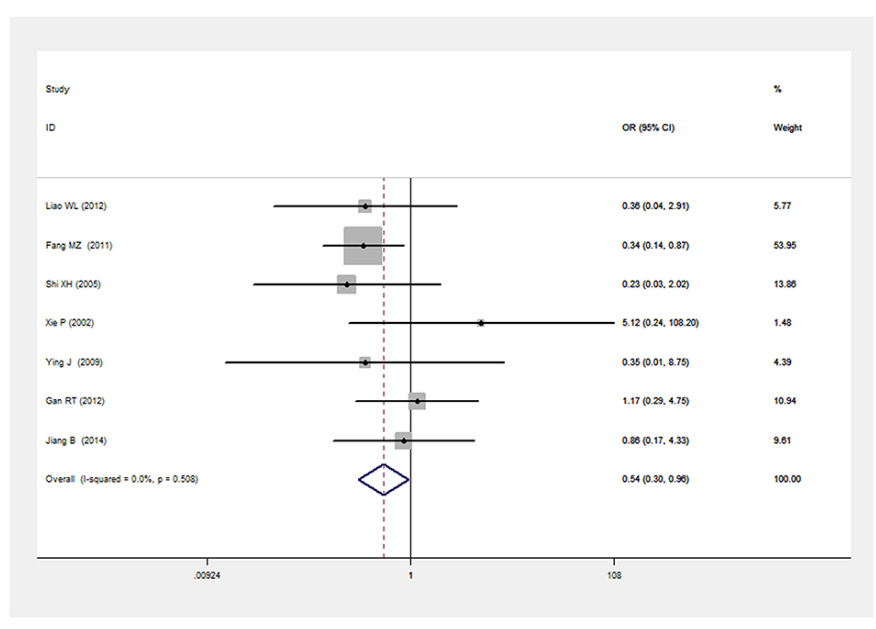

Figure 4: Forest plot of T2DM associated with $L E P R$ GIn223Arg gene polymorphism under a recessive genetic model (AA vs. GG+GA).

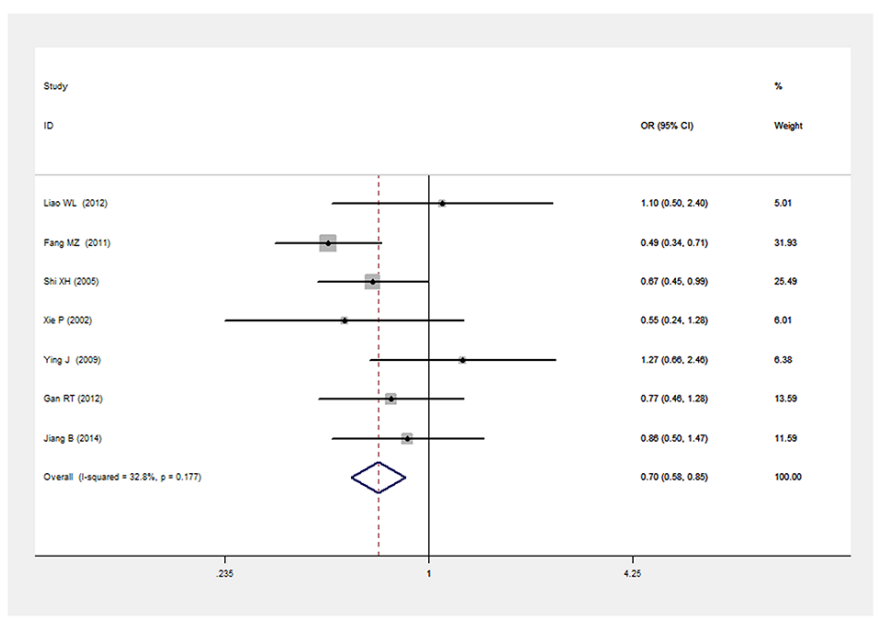

Figure 5: Forest plot of T2DM associated with $L E P R$ Gln223Arg gene polymorphism under a heterozygous genetic model (GA vs. GG). 
T2DM is a polygenic disease which is closely related with obesity, hypertension, gout, and lipid metabolism disorder. T2DM is clinically called insulin resistance (IR) syndrome, the core of which is the IR. Recently many studies have shown that the leptin resistance might still exist in the IR patients at the same time [15]. Leptin is a fat-derived hormone which could play a role in the regulating the energy metabolism and body lipid homeostasis after it is combined with the LEPR located in the hypothalamus and adipose tissue. Hence, the $L E P R$ gene is also called T2DM gene.

What mechanisms can explain the increased risk of T2DM associated with this polymorphism? One possible mechanism is that the glutamine residue may

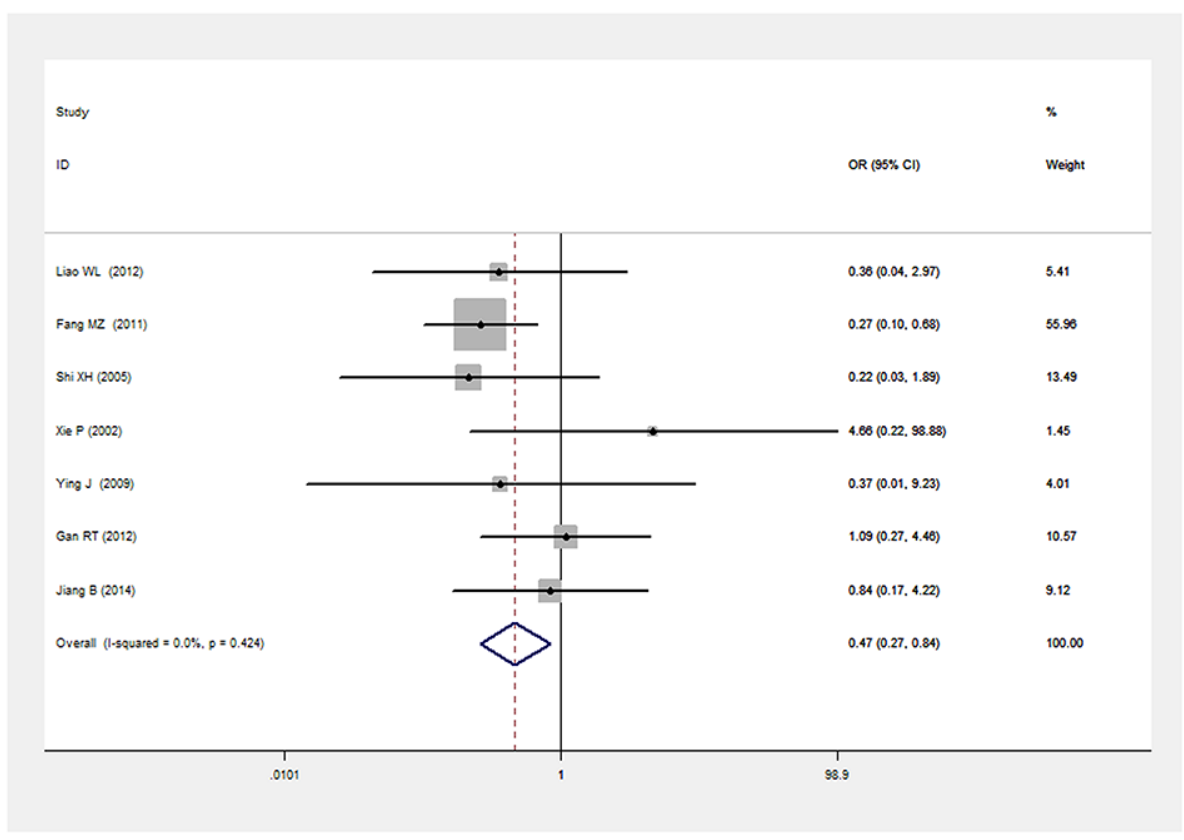

Figure 6: Forest plot of T2DM associated with LEPR GIn223Arg gene polymorphism under a homozygous genetic model (AA vs. GG).

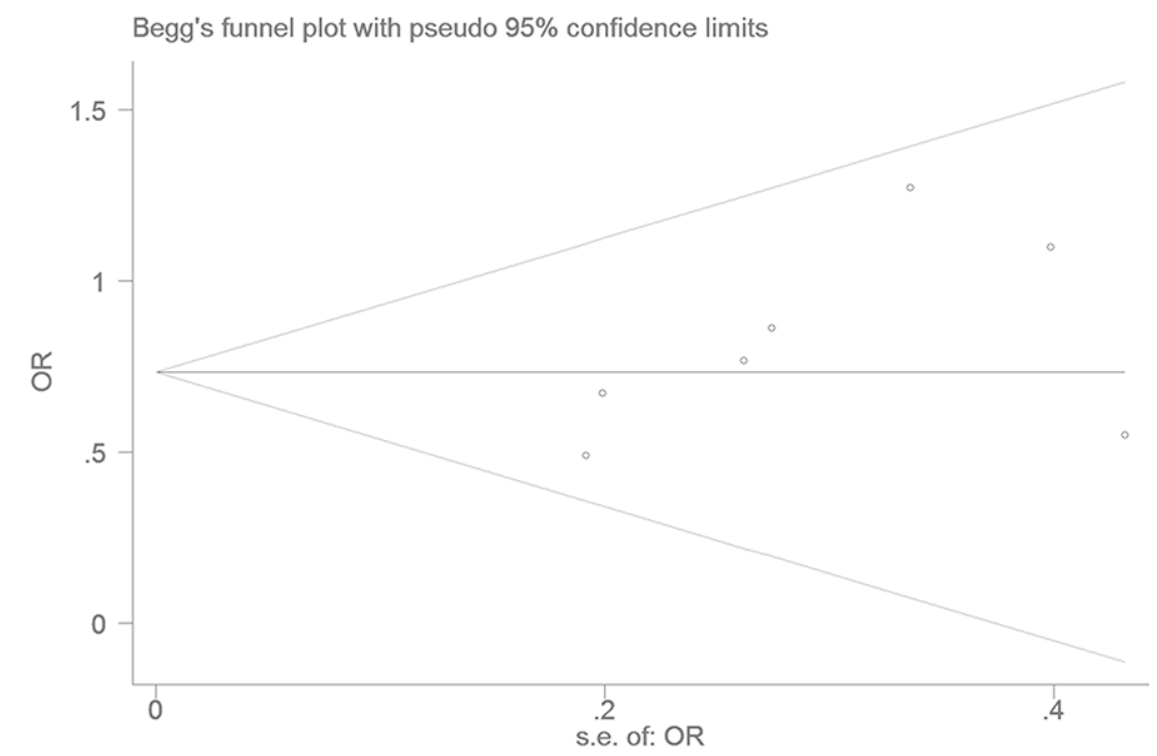

Figure 7: Funnel plot for studies of the association of T2DM associated and LEPR GIn223Arg gene polymorphism under a heterozygous genetic model (GA vs. GG). The horizontal and vertical axis correspond to the OR and confidence limits. OR: odds ratio; SE: standard error. 
Table 2: Summary of meta-analysis of association between $L E P R$ gene Gln223Arg polymorphism and T2DM in the Chinese population

\begin{tabular}{lccccccc}
\hline Genetic model & $\begin{array}{c}\text { Pooled OR (95\% } \\
\text { CI) }\end{array}$ & $\begin{array}{c}\mathbf{Z} \\
\text { value }\end{array}$ & P value & Study number & T2DM size & control size & $\boldsymbol{P}_{\text {heterogeneity(I2\%) }}$ \\
\hline $\begin{array}{l}\text { Allele } \\
\text { genetic model }\end{array}$ & $1.432(1.211-1.694)$ & 4.20 & $2.67 \times 10^{-5^{*}}$ & 7 & 2084 & 1283 & $0.151(36.3 \%)$ \\
$\begin{array}{l}\text { Dominant } \\
\text { genetic model }\end{array}$ & $1.466(1.215-1.769)$ & 4.00 & $6.33 \times 10^{-5^{*}}$ & 7 & 2084 & 1283 & $0.126(39.8 \%)$ \\
$\begin{array}{l}\text { Recessive } \\
\text { genetic model }\end{array}$ & $0.539(0.303-0.960)$ & 2.10 & $0.036^{*}$ & 7 & 2084 & 1283 & $0.508(0 \%)$ \\
$\begin{array}{l}\text { Heterozygous } \\
\text { genetic model }\end{array}$ & $0.700(0.577-0.849)$ & 3.61 & $3.06 \times 10^{-4^{*}}$ & 7 & 2084 & 1283 & $0.177(32.8 \%)$ \\
$\begin{array}{l}\text { Homozygous } \\
\text { genetic model }\end{array}$ & $0.472(0.265-0.839)$ & 2.56 & $0.011^{*}$ & 7 & 2084 & 1283 & $0.424(0 \%)$ \\
\hline
\end{tabular}

$* \mathrm{P}<0.05$.

CI: confidence interval; OR: odds ratio; T2DM size: the total number of T2DM cases; control size: the total number of control group; allele genetic model: G vs. A; dominant genetic model: GG vs. GA+AA; recessive genetic model: AA vs. GA+ GG; heterozygous genetic model: GA vs. GG; homozygous genetic model: AA vs. GG.

cause reduced LEPR expression on the plasma membrane impairing signal transduction through the receptor. It also could increase risk of T2DM by influencing neurological function of the vagus nerve.

The vagus nerve sensibility for the insulin secretion were reduced and further led to the IR, disrupting, not only glucose metabolism, but also fat metabolism. The IR not only makes the glucose metabolism disturbance, but also the fat metabolism disturbance. Although these mechanisms have yet to be demonstrated physiological, they provide a plausible rationale for the results from this study [5].

Liu et al and Su et al. both performed meta-analysis on the association between LEPR Gln223Arg gene polymorphism and T2DM in 2015 and 2016, respectively $[16,17]$. They both concluded that LEPR Gln223Arg gene polymorphism had no effect on the susceptibility with T2DM. Both of these papers, however, do not take into account differences in ethnicity. Liu's meta-analysis grouped all Asians, including Koreans, Indians, Malaysia, and Chinese in to a single subgroup while Su's meta-analysis analyzed data that combined Asians and Europeans. These meta-analyses also included studies with the controls' genotype number that deviated from HWE, such as individual studies by Zhang, Zhao, and Liu [8-10]. These factors combined may help account for the differences in results and also lend further credibility to the results of this study.

Our study is not without limitations, however, as our results do not replace the need for more large-scale studies on the association of T2DM with LEPR Gln223Arg gene polymorphism. It also fails to take into account other possibly significant factors that play a role in determining plasma LEPR levels [18].

In conclusion, we found a significant association between the LEPR Gln223Arg gene polymorphism and increased T2DM risk in the Chinese population. Chinese carriers of the G allele of LEPR Gln223Arg gene polymorphism may be more susceptible to T2DM. This conclusion clarifies the mixed results on the topic and develops our understanding of T2DM so that in the future, we can develop personalized treatment strategies for our patients. Taking account the above mentioned limitations, more research is required to verify this conclusion.

\section{MATERIALS AND METHODS}

\section{Publication search and inclusion criteria}

The keywords LEPR, Q223R or Gln223Arg, rs1137101, T2DM, diabetic, and diabetes were searched in on PubMed, the Web of Science, Embase, the China National Knowledge Infrastructure, the China Biological Medicine Database, the VIP database, and the Wanfang database.

In order to meet inclusion criteria, the paper had to a) evaluate the association between $L E P R$ Gln223Arg gene polymorphism and T2DM b) diagnose T2DM based on criteria determined by the World Health Organization in 1999 (i.e. definite medical history of T2DM medical history and fasting plasma glucose $>7.0 \mathrm{mmol} / \mathrm{L}$ or plasma glucose $>11.1 \mathrm{mmol} / \mathrm{L}$ two hours after oral glucose tolerance test) c) be case-controls or cohort studies published in official journals d) have a control group whose genotype is at HWE. e) have cases where allele and genotype frequencies and their corresponding controls were available.

Studies that evaluated the association of LEPR gene Gln223Arg polymorphism with other related conditions, such as Type 1 diabetes mellitus, obesity, or hypertension, were excluded. Participants with diseases of the heart, 
liver, kidney, and the urinary tract were also excluded. The Newcastle-Ottawa Scale (NOS) was used to assess the quality of the included studies.

\section{Data extraction}

Included data was abstracted through a standardized protocol of three researchers. Two researchers identified studies for inclusion independently, while a third acted as a mediator to resolve any disagreements between the two. Studies that violated the inclusion criteria, were published repeatedly, or lacked adequate data were rejected. Data sets used by the same authors for multiple papers were included in our analysis once. Table 1 displays the first author's name, publication year, region, matching criteria, genotype number, and total number of cases and controls.

\section{Statistical analysis}

Statistical analysis was performed using STATA 12.0 software (StataCorp, College Station, TX). Five genetic models, allelic (total $\mathrm{G}$ vs. total $\mathrm{A}$ ), dominant (GG vs. GA+AA), recessive (AA vs. GA+GG), homozygous (AA vs. GG), and heterozygous genetic models (GA vs. GG) were adopted for the current meta-analysis. The association of $L E P R$ Gln223Arg gene polymorphism with T2DM was evaluated using odds ratio (OR) and their corresponding 95\% confidence intervals. Heterogeneity between the individual studies was calculated by the Chisquare-based Q-test [19]. Due to the lack of heterogeneity among the studies, the pooled OR was estimated using the fixed-effects model (the Mantel-Haenszel method) [20]. Z-test was used to determine the pooled OR and the significance was set at $\mathrm{P}<0.05$ level. The Fisher's exact test was used to evaluate the HWE. The potential publication bias was assessed by using the funnel plot. The funnel plot asymmetry was evaluated by using the Egger's linear regression test on the OR. The significance was set at $\mathrm{P}<0.05$ level in all of the above mentioned tests [21].

\section{Abbreviations}

LEPR: leptin receptor; T2DM: Type 2 diabetes mellitus; ORs: odds ratios; 95\% CI: 95\% confidence intervals; DM: diabetes mellitus; NPY: neuropeptide Y; HWE: Hardy-Weinberg equilibrium; IR: insulin resistance; NOS: Newcastle-Ottawa Scale.

\section{Author contributions}

Conception and design: Y.L. and H.W.; Administrative support: Z.Y., and L.W. Provision of study materials: Y.L., H.W., J.W., X.Y. and H.G.; Collection and assembly of data: Y.L, X.Y. and H.G. Data analysis and interpretation: Y.L, X.Y., H.W. and H.K. Manuscript writing: All authors; Final approval of manuscript: All authors.

\section{ACKNOWLEDGMENTS}

Thank all our colleagues working in the Department of gerontology, the First Affiliated Hospital of Nanjing Medical University.

\section{CONFLICTS OF INTEREST}

No conflict of interest existed in the current metaanalysis.

\section{FUNDING}

This work was funded by the National Natural Science Foundation of China (NSFC 81100073 to Dr Yan-yan Li), Excellent Young and Middle-Aged Teachers Assistance Program of Nanjing Medical University for Dr Yan-yan Li (2013-2015, JX2161015034) and the Priority Academic Program Development of Jiangsu Higher Education Institutions (PAPD). This work was also funded by the Natural Science Foundation of Jiangsu Province (BK 2012648 to Dr Hui Wang), "six talent peaks" project in Jiangsu Province (2015WSN-033).

\section{REFERENCES}

1. Xu Y, Wang L, He J, Bi Y, Li M, Wang T, Wang L, Jiang Y, Dai M, Lu J, Xu M, Li Y, Hu N, et al. Prevalence and control of diabetes in Chinese adults. JAMA. 2013; 310:948-59. doi: 10.1001/jama.2013.168118.

2. Kieffer TJ, Heller RS, Leech CA, Holz GG, Habener JF. Leptin suppression of insulin secretion by the activation of ATP-sensitive $\mathrm{K}+$ channels in pancreatic beta-cells. Diabetes. 1997; 46:1087-93.

3. Emilsson V, Liu YL, Cawthorne MA, Morton NM, Davenport M. Expression of the functional leptin receptor mRNA in pancreatic islets and direct inhibitory action of leptin on insulin secretion. Diabetes. 1997; 46:313-6.

4. Yiannakouris N, Yannakoulia M, Melistas L, Chan JL, Klimis-Zacas D, Mantzoros CS. The Q223R polymorphism of the leptin receptor gene is significantly associated with obesity and predicts a small percentage of bodyweight and body composition variability. J Clin Endocrinol Metab. 2001; 86:4434-9.

5. Ying J, Shi NS, Pan RW, Li PZ, Zhang HQ. Association between Gln223Arg and type 2 diabetes in Zhejing. Chin Gerontol. 2009; 29:858-60.

6. Fang MZ. Association between LEPR gene variation and bone metabolism in II diabetes mellitus. Kumings: Kunming Medical University, 2001; p31.

7. Shi XH, Sun L, Wang L, Jin F, Zhu XQ, Tang L, Yang Z. Association between Gln223Arg gene polymorphism and type 2 diabetes mellitus in Chinese north population. Med Res J. 2012; 41:23-6. 
8. Zhang YD, Li G, Zhang MJ, Teng XC, Chen CQ, Tang XJ. Association between Gln223Arg and type 2 diabetes. J Third Mil Med Univ. 2011; 33:1932-4.

9. Zhao LS, Xiang GD, Tang Y, Hou J, Liao YH, Yang L, Le L, Zuo J. Association between Gln223Arg and type 2 diabetes in Wuhan. Mil Med J South Chin. 2008; 22:25-9.

10. Liu Y. Research of susceptibility genes about type 2 diabetes mellitus in Chinese north population. Huhhot: Inner Mongolia Normal University, 2004; p32.

11. Liao WL, Chen CC, Chang CT, Wu JY, Chen CH, Huang YC, Tsai CH, Tsai FJ. Gene polymorphisms of adiponectin and leptin receptor are associated with early onset of type 2 diabetes mellitus in the Taiwanese population. Int J Obes (Lond.) 2012; 36:790-6.

12. Xie $\mathrm{P}$, Zhang J, Deng ZX, Wang SQ, Xu L. Association between LEPR genetic variation and obesity and high blood pressure in type 2 diabetes patients. Chin Healthy Birth Genet. 2002; 10:34-5.

13. Gan RT, Yang SS. The $223 \mathrm{~A}>\mathrm{G}$ polymorphism of the leptin receptor gene is associated with macroangiopathy in type 2 diabetes mellitus. Mol Biol Rep. 2012; 39:4759-64.

14. Jiang B, Liu Y, Liu Y, Fang F, Wang X, Li B. Association of four insulin resistance genes with type 2 diabetes mellitus and hypertension in the Chinese Han population. Mol Biol Rep. 2014; 41:925-33.
15. Rahmouni K, Haynes WG. Leptin and the cardiovascular system. Recent Prog Horm Res. 2004; 59:225-44.

16. Liu Y, Chen SQ, Jing ZH, Hou X, Chen Y, Song XJ, Lv WS, Wang R, Wang YG. Association of LEPR Gln223Arg polymorphism with T2DM: a meta-analysis. Diabetes Res Clin Pract.2015; 109:e21-6.

17. Su S, Zhang C, Zhang F, Li H, Yang X, Tang X. The association between leptin receptor gene polymorphisms and type 2 diabetes mellitus: a systematic review and metaanalysis. Diabetes Res Clin Pract. 2016;121:49-58.

18. He M, Fu QX, Li H, Jin YN, Tang XJ. Correlation between leptin receptor gene polymorphism and type 2 diabetes in Chinese population: a meta-analysis. Med J Chin PLA. 2015; 40:809-15.

19. Cochran WG. The effectiveness of adjustment by subclassification in removing bias in observational studies. Biometrics.1968; 24:295-313.

20. Mantel N, Haenszel W. Statistical aspects of the analysis of data from retrospective studies of disease. J Natl Cancer Inst. 1959; 22:719-48.

21. Egger M, Davey Smith G, Schneider M, Minder C. Bias in meta-analysis detected by a simple, graphical test. Br Med J. 1997; 315:629-34. 